\title{
Geographic range predicts photosynthetic and growth response to warming in co-occurring
} tree species

\author{
Peter B. Reich ${ }^{1,2 \star}$, Kerrie M. Sendall', Karen Rice', Roy L. Rich', Artur Stefanski', Sarah E. Hobbie ${ }^{3}$ \\ and Rebecca A. Montgomery ${ }^{1}$
}

Populations near the warm edge of species ranges may be particularly sensitive to climate change ${ }^{1-4}$, but lack of empirical data on responses to warming represents a key gap in understanding future range dynamics. Herein we document the impacts of experimental warming on the performance of 11 boreal and temperate forest species that co-occur at the ecotone between these biomes in North America ${ }^{5}$. We measured in situ net photosynthetic carbon gain and growth of $>4,100$ juvenile trees from local seed sources exposed to a chamberless warming experiment that used infrared heat lamps and soil heating cables to elevate temperatures by $+3.4^{\circ} \mathrm{C}$ above- and belowground ${ }^{6}$ for three growing seasons across $\mathbf{4 8}$ plots at two sites. In these ecologically realistic field settings, species growing nearest their warm range limit exhibited reductions in net photosynthesis and growth, whereas species near their cold range limit responded positively to warming. Differences among species in their three-year growth responses to warming parallel their photosynthetic responses to warming, suggesting that leaf-level responses may scale to whole-plant performance. These responses are consistent with the hypothesis, from observational data and models ${ }^{4,7-10}$, that warming will reduce the competitive ability of currently dominant southern boreal species compared with locally rarer co-occurring species that dominate warmer neighbouring regions.

Co-occurring species at boreal-temperate ecotones may respond differently to climate warming, triggering changes in their competitive hierarchies, and thus in species composition ${ }^{1,2}$. One metric that could indicate such differences is the location of local populations relative to key features of species geographic distributions, such as range limits ${ }^{3,7-10}$. Even locally adapted populations of co-occurring species might differ in terms of how well suited they are to the local thermal environment. Boreal species with generally colder distributions and greater cold tolerance ${ }^{11,12}$ may have lower capacity to improve their performance with projected higher temperatures than less cold-tolerant temperate species, because of trade-offs between cold tolerance and growth capacity $^{13-15}$. Boreal species may also be more sensitive to heat waves and associated droughts than temperate species. Moreover, as widely distributed species commonly display ecotypic variation across the environmental gradients spanned by their ranges ${ }^{16-18}$, intraspecific genotypic variation within co-occurring species could further shape differences in their responses to climate warming ${ }^{3,4,19}$.
For example, populations near the cold edge of a species' distribution may receive genes from populations from warmer climates, and thus contain genetic material that enables successful growth in a warming climate. In contrast, populations near the warm edge of their range cannot receive genes from populations in warmer climates, because such populations do not exist. Any, or all, of these differences could result in boreal species near the warm edge of their range having limited capacity to respond positively to further warming compared to temperate species near their cold range limit. These kinds of species differences in responsiveness to climate warming could lead to major compositional shifts at broad ecotones, including the boundary between the vast boreal and temperate forest biomes ${ }^{7,9,10,20}$.

Many tree species co-occur at the boreal-temperate ecotone, but otherwise have markedly distinct geographic distributions. For example, in northern Minnesota, USA, roughly half of the abundant species $^{5}$ are boreal (extending to northern Canada but not much further south in the US) and half are temperate (extending further south in the US, but with northern range limits not much beyond the US/Canada border) $)^{21,22}$.

The co-occurrence in the southern boreal ecotone of species with markedly distinct ranges provides an opportunity to address the hypothesis that boreal tree species near their warmer range limits will exhibit negative or neutral responses to future warming, whereas coexisting temperate species near their cold range limits will have neutral or positive responses, facilitating forest compositional change. This hypothesis is implicit in 'climateenvelope' models, even those with modifications for plant sensitivities to resources and environments ${ }^{10,23-26}$. However, it is also possible that, despite large differences in overall geographic distribution, strong local adaptation of near range-edge populations could result in co-occurring species having a similar capacity to respond physiologically to future warming.

Herein we present results of a three-year chamberless field experiment ${ }^{6}$ that tested these hypotheses by exposing juveniles of 11 tree species to ambient and elevated $\left(+3.4^{\circ} \mathrm{C}\right)$ growing season temperatures and measuring their physiological and growth responses. Juveniles ( $\sim 3$ years old in 2009) of ten native and one naturalized species from northern Minnesota seed sources were planted in 2008 into existing vegetation in both open (cleared) and closed canopy (understory) forest habitats at two sites ( $\sim 150 \mathrm{~km}$ apart) in northeastern Minnesota, USA (Supplementary Table 1). Plants grew in ecologically realistic densities of neighbouring herb, shrub

${ }^{1}$ Department of Forest Resources, University of Minnesota, St Paul, Minnesota 55108, USA. ${ }^{2}$ Hawkesbury Institute for the Environment, University of Western Sydney, Penrith, New South Wales 2753, Australia. ${ }^{3}$ Department of Ecology, Evolution, and Behavior, University of Minnesota, St Paul, Minnesota 55108, USA. *e-mail: preich@umn.edu 
Table 1 | Analysis of variance of site, species, canopy, and warming treatments on growth (stem dry biomass) and photosynthesis.

\begin{tabular}{|c|c|c|c|c|}
\hline \multirow{2}{*}{$\begin{array}{l}\text { Whole model } \\
\text { Effect }\end{array}$} & \multicolumn{2}{|c|}{$\begin{array}{c}\text { Growth } \\
R^{2}=0.741, P<0.0001 \\
n=4,118\end{array}$} & \multicolumn{2}{|c|}{$\begin{array}{c}\text { Photosynthesis } \\
R^{2}=0.380, P<0.0001 \\
n=4,412\end{array}$} \\
\hline & F Ratio & Prob $>$ F & F Ratio & Prob $>$ F \\
\hline Site & 71.1579 & $<0.0001$ & 166.2461 & $<0.0001$ \\
\hline Species & 129.3839 & $<0.0001$ & 146.7678 & $<0.0001$ \\
\hline Canopy & 375.0851 & $<0.0001$ & 155.3597 & $<0.0001$ \\
\hline Warming & 2.6024 & 0.1145 & 0.4183 & 0.5206 \\
\hline Site $*$ Species & 31.8050 & $<0.0001$ & 2.7572 & 0.0022 \\
\hline Site*Canopy & 0.3395 & 0.5633 & 0.0447 & 0.8335 \\
\hline Site $*$ Warming & 2.1981 & 0.1459 & 0.7999 & 0.3752 \\
\hline Species*Canopy & 56.1633 & $<0.0001$ & 15.0940 & $<0.0001$ \\
\hline Species $*$ Warming & 14.1154 & $<0.0001$ & 5.6932 & $<0.0001$ \\
\hline Canopy*Warming & 1.7053 & 0.1989 & 2.6462 & 0.1098 \\
\hline $\begin{array}{l}\text { Site } * \text { Species } * \\
\text { Canopy }\end{array}$ & 6.4689 & $<0.0001$ & 1.8388 & 0.0491 \\
\hline $\begin{array}{l}\text { Site } * \text { Species } * \\
\text { Warming }\end{array}$ & 3.6050 & $<0.0001$ & 0.7127 & 0.7133 \\
\hline $\begin{array}{l}\text { Site } * \text { Canopy } * \\
\text { Warming }\end{array}$ & 5.3458 & 0.0259 & 0.2640 & 0.6095 \\
\hline $\begin{array}{l}\text { Species*Canopy* } \\
\text { Warming }\end{array}$ & 2.1546 & 0.0178 & 0.7825 & 0.6459 \\
\hline $\begin{array}{l}\text { Site } * \text { Species } * \\
\text { Canopy } * \text { Warming }\end{array}$ & 0.5355 & 0.8661 & 0.4523 & 0.9206 \\
\hline Diameter (2008) & 807.7398 & $<0.0001$ & & \\
\hline Height (2008) & 245.4791 & $<0.0001$ & & \\
\hline
\end{tabular}

For growth, diameter and height (both $\log _{10}$ ) in 2008 were used as covariates. The $\mathrm{F}$ ratio is the ratio of the variance explained by each effect term (individual effect or interaction) to the total unexplained variance. Prob $>\mathrm{F}$ is the probability, expressed as a fraction of 1 , that the response observed in relation to each effect term would occur by random chance. Thus, low values (for example, $<0.05$ ) indicate a high certainty that the effect noted was real, rather than a chance event.

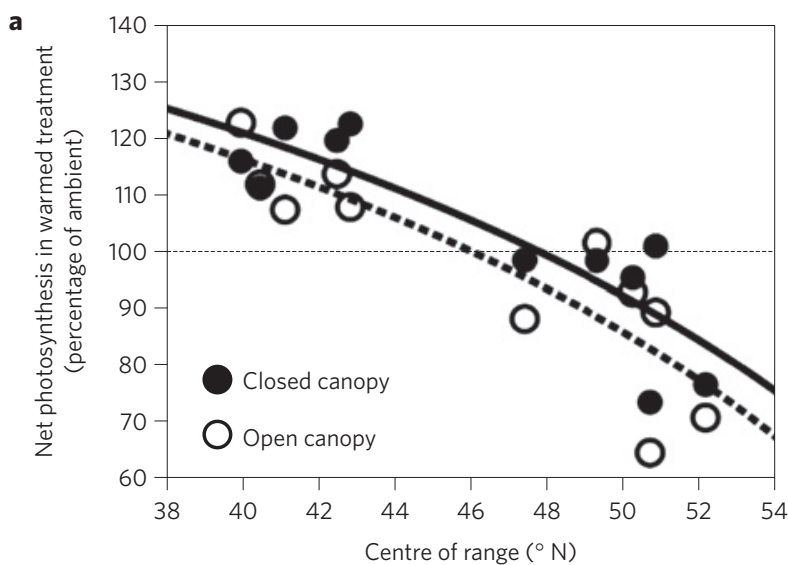

and tree species, and thus the observed performance of each species represents their response to warming in a setting that included interactions, such as competition, with other plants. Although the study species are often lumped into boreal and temperate groups, their distributions represent continua (Supplementary Fig. 1), and we evaluated whether two complementary indices of distributions were related to species' responses to climate warming. One index, based on a mapped continent-wide distribution ${ }^{21,22}$, is the centre of the latitudinal range in central North America. A second, and more regional, index quantifies for each species the percentage of their regional relative abundance that occurs in the northern half of six ecotonal counties in northeastern Minnesota. See Supplementary Information for details. The two measures of geographic distribution are significantly $(r=0.90, P<0.001)$ linearly correlated (Supplementary Fig. 2).

As hypothesized, over three growing seasons, net photosynthetic carbon gain and juvenile tree growth were adversely impacted by experimental warming for boreal species growing furthest south of the centre of their range, near their warm range limit, but were stimulated for co-occurring temperate species growing north of the centre of their range, near their cold range limit (Table 1, Figs 1 and 2, and Supplementary Fig. 3). The analyses of variance of experimental treatments across all species, sites and canopy conditions showed significant interaction between species and warming treatment for both growth and net photosynthesis $(P<0.0001$, Table 1$)$; species differed in the direction (positive, neutral, negative) and magnitude of response to warming. Overall responses of net photosynthesis and growth to warming (on average across species) did not differ by site (that is, no site $*$ warming interactions, $P>0.05$ ).

Measures of species' broad and local geographic distributions predicted whether response to warming was positive, negative, or neutral. Both net photosynthetic and growth responses to warming were negative for species growing south of their range centre (Figs 1a and 2a) and that were more abundant in the northern than the southern part of the ecotone (Figs $1 \mathrm{~b}$ and $2 \mathrm{~b}$ ). In contrast, responses were positive for those growing north of their range centre and that had relatively low abundance in the northern part of the ecotone. This was true in both open and

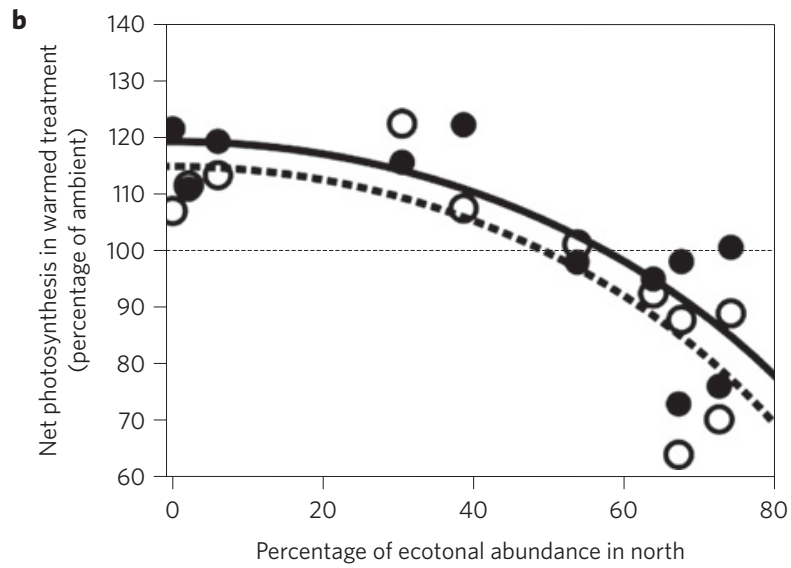

Figure 1 | Effect of warming on in situ net photosynthesis in relation to metrics of species geographic distribution. a,b, Light-saturated net photosynthesis in warmed treatment in northern Minnesota as a percentage of net photosynthesis in ambient treatment is shown in relation to the centre of the latitudinal range in central North America (a) and percentage of ecotonal abundance that occurs in the northern part of the ecotone (b; defined as the percentage of each species' regional relative abundance that occurs in the northern half of six ecotonal counties in northeastern Minnesota, for 11 native and naturalized species growing in open and closed canopy conditions. Relative abundance in the northern three and southern three counties of the region were equally weighted to eliminate sample size differences. Open conditions (open circles, dotted lines); closed conditions (filled circles, solid lines). Data are averaged across two sites from 4,412 measurements made in 2009, 2010 and 2011. Lines represent best statistical fits (in all cases using squared terms for both dependent and independent variables): (a) $R^{2}=0.78$ and 0.77 for open and closed conditions, respectively, $P<0.0001$; (b) $R^{2}=0.70$ and 0.74 for open and closed conditions, respectively, $P<0.0001$. Dotted line is at $100 \%$; values above the line indicate that warming increases photosynthesis; below the line indicates reduced photosynthesis. 

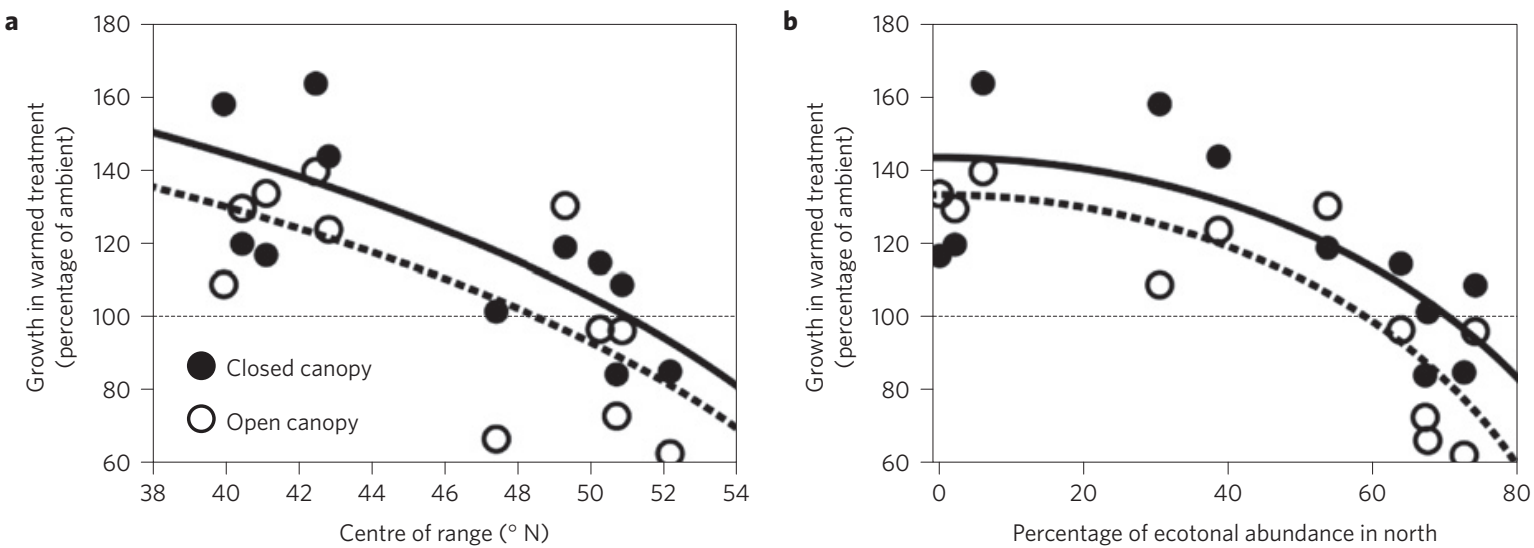

Figure 2 | Effect of warming on stem biomass growth in relation to metrics of species geographic distribution. $\mathbf{a}$, $\mathbf{b}$, Stem dry biomass in northern Minnesota after three years in warmed treatment as a percentage of stem dry biomass in ambient treatment is shown in relation to the centre of the latitudinal range (a) and percentage of ecotonal abundance in the northern part of the ecotone (b; see Fig. 1 for details), for 11 native and naturalized species growing in open and closed canopy conditions. Open conditions (open circles, dotted lines); closed conditions (filled circles, solid lines). Data are averaged across two sites from 4,118 individuals based on size late in the 2011 growing season, using 2008 diameters (of each sapling) as a covariate. Lines represent best statistical fits (in all cases using squared terms for both dependent and independent variables): (a) $R^{2}=0.49$ and 0.53 for open and closed conditions, respectively, $P<0.0001 ;(\mathbf{b}) R^{2}=0.74$ and 0.52 for open and closed conditions, respectively, $P<0.0001$. Dotted line is at $100 \%$; values above the line indicate that warming increases growth; below the line indicates reduced growth.

understory habitats, and across sites. Across species, the impact of warming on net photosynthesis was dominated by changes in gross photosynthesis, as warming-induced increases in respiration rates that occurred in all species (data not shown) were more than an order of magnitude smaller than the warming-induced shifts in net photosynthetic rates for the species furthest from their range centres.

As the boreal and temperate groups both included species differing widely in shade tolerance $\mathrm{e}^{21,22,27,28}$, whether responses to warming were similar or different in open versus understory conditions was of particular interest. The interaction of treatment and canopy condition was not significant for net photosynthesis or growth (Table 1), indicating a generally similar response to warming in both open and closed canopy settings, despite a slightly more positive response on average in understory than open conditions (Figs 1 and 2). Moreover, the shape of the relationship between response to warming and geographic range metrics did not differ by canopy type for any of the four cases shown in Figs 1 and 2 (see Supplementary Methods for details).

The two species nearest their warm edge limit (balsam fir, Abies balsamea, and white spruce, Picea glauca) were most adversely influenced by warming (net photosynthesis and growth were reduced by $\sim 25 \%$ on average). In contrast, temperate maple (Acer) and oak (Quercus) species, and non-native common buckthorn (Rhamnus cathartica) had enhanced photosynthesis (by $15 \%$ on average) and growth (by $30 \%$ on average) in warmed conditions. The remaining species (Pinus, Betula, Populus) had intermediate responses to warming, on average. The nonlinear responses (Figs 1 and 2) suggest increasing sensitivity to warming for species closest to their southern range margins.

Net photosynthetic response to warming was a good predictor of the growth response to warming (Fig. 3). In both open and closed canopy conditions, species that responded positively to warming in terms of net photosynthesis had positive growth responses to warming, and those with negative net photosynthetic responses grew more slowly in warmed treatments. The concordance of effects of warming on photosynthesis and growth suggests that physiological carbon gain responses to warming play an important role in longer-term integrated growth responses and could be one mechanism contributing to potential future shifts in species abundances across the ecotone.
Given that the densities of neighbouring plants, including of the other planted tree species, were high, as is typical for this ecosystem on these sites, the response to the climate warming treatment of each tree species may reflect a combination of the direct effect of warming and indirect effects of either heightened or reduced competition from neighbours as a result of their responses to warming. Thus, the results are best interpreted through the lens of the realized niche (how will these species respond to climate change when interactions with other species are included?) than the fundamental niche (what temperature range can these species physiologically tolerate?).

As our experiment did not warm during winter, our results reflect ways only in which growing season warming might influence forests. Winter warming could influence species performance in ways that might favour or disfavour the temperate species. For example, winter warming might alleviate adverse responses to mid-winter extreme cold periods for temperate species that are less cold-tolerant than boreal species ${ }^{11}$. Thus, year-round warming might have been more favourable to temperate than boreal species and led to even larger differences in response between boreal versus temperate species. However, warmer winters might also reduce snowpack, reducing insulation of soils and leading to freezing soil temperatures; moreover, warm spells in late winter could cause species to break bud earlier, making them susceptible to freezing events. Such adverse effects of warmer winters could be more pronounced for the less cold-tolerant temperate species. It is unknown whether future winter conditions will more frequently favour or disfavour temperate species, as such predictions are beyond the capability of today's climate and ecological models. Regardless, both growing season and winter effects are clearly important; we focused on the growing season in our study because our warming techniques are better suited to testing growing season than winter effects.

Whether responses to warming of larger individuals will mirror those of juveniles is uncertain. However, given the compounding nature of differences in early growth to differences in future performance, it is likely that juvenile responses to warming will be consequential for subsequent individual performance and for community composition. Moreover, the consistency of responses in open and shaded canopy conditions (at two sites) further supports the notion that the differential responses to warming among species would be robust to spatial and temporal variation in light availability, as might occur among micro-sites or through stand 


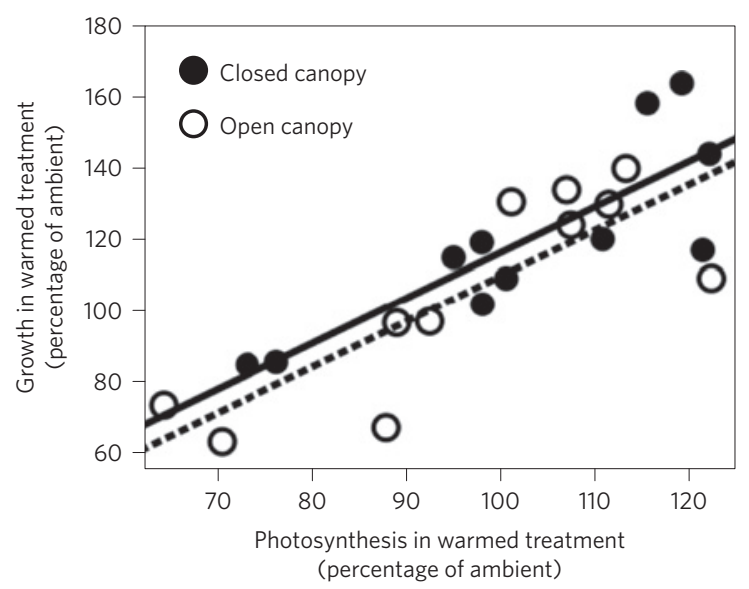

Figure 3 | Growth response to warming in relation to net photosynthetic response to warming. Stem dry biomass after three years in warmed treatment as a percentage of stem dry biomass in ambient treatment is shown in relation to photosynthesis in warmed treatment as a percentage of photosynthesis in ambient treatment, for 11 native and naturalized species growing in open and closed canopy conditions. Correlations: $R^{2}=0.68$ and 0.70 for open and closed conditions, respectively, $P<0.0001$. See also legends for Figs 1 and 2 .

development. It is likely, therefore, that these data signal much about how biome transition might be driven by warming and competition.

As the range of the non-native Rhamnus species is influenced both by the predominance of source populations in towns and cities located largely south of the ecotone, and by climate suitability, it is impossible to say whether its rarity in and north of the ecotone is due to cold climate or lack of propagules. However, as it performed better in warmed conditions, it will probably become more invasive further north with climate change.

Despite large differences in geographic distribution, all 11 species co-occur in northern Minnesota; thus local adaptation could have resulted in local ecotypes responding similarly to warming in terms of their overall net carbon budgets, as was true for acclimation of the photosynthetic temperature response function to warming ${ }^{29}$. However, for net photosynthesis and growth integrated over time, species did not respond similarly to warming-species near their cold range limits performed better with warming than those near their warm range limits. Hence, key aspects of species' biology are reflected in their geographic distributions. Moreover, our results indicate that broader geographic distributions can indeed predict a differential response to climate warming ${ }^{30}$ at this ecotone $e^{10}$, and, at least for this set of important North American cold temperate and boreal species, climate-envelope models may accurately project future forests in the ecotone. Growth responses to summer temperatures of naturally occurring saplings across northern Minnesota suggest that rank reversal in growth performance (of boreal conifers versus temperate angiosperms) may already be happening ${ }^{9}$, consistent with results of the present study and of the climate-envelope models.

The divergent response to experimental warming of species near their cold versus warm range limit suggests that warmer growing seasons will shift competitive hierarchies, by reducing the competitive ability of currently dominant boreal species, especially when compared to less common co-occurring species that dominate warmer neighbouring regions. This in turn will probably alter forest composition, leading either to more temperate forest-like vegetation if better-performing temperate species, most of which are at present rare at the southern boreal forest ecotone ${ }^{5}$, are sufficiently abundant locally to increase population growth and abundance regionally, or to more shrub-like vegetation otherwise. At present, southern boreal forests are dominated by species that are near their warm range limit, and their replacement by temperate species could take decades to centuries. There is considerable uncertainty about this timing, however, because climate change could also affect natural (for example, wildfire, windstorm, herbivory) and anthropogenic (for example, timber harvest) disturbance regimes that could contribute to the rate and direction of compositional change ${ }^{9,31,32}$. What is more certain from our results, as well as those of long-term inventory data $^{7,8}$ and gradient studies ${ }^{9}$, is a moderately high probability that climate change will result in poor growing season performance by boreal forest trees in areas where they are at present most productive and most densely populated by humans.

\section{Methods}

Site description and experimental design. The experiment is located at two University of Minnesota field stations; the Cloquet Forestry Center, Cloquet MN $\left(46^{\circ} 40^{\prime} 46^{\prime \prime} \mathrm{N}, 92^{\circ} 31^{\prime} 12^{\prime \prime} \mathrm{W}\right)$ and $\sim 150 \mathrm{~km}$ further north, the Hubachek Wilderness Research Center, Ely, MN ( $\left.47^{\circ} 56^{\prime} 46^{\prime \prime} \mathrm{N}, 91^{\circ} 45^{\prime} 29^{\prime \prime} \mathrm{W}\right)$. Weather stations nearest the two sites report that mean annual and seasonal temperatures from 1973 to 2008 were $\sim 2.2^{\circ} \mathrm{C}$ cooler and mean annual precipitation was $\sim 7 \%$ lower near the northern (Ely) than near the southern site (Cloquet;

Supplementary Table 1). During the experimental period (2009-2011), conditions at both weather stations were not atypical from long-term trends. Temperatures by season and year were on average slightly warmer and precipitation was slightly lower in 2009-2011 than in 1973-2008. Site-based monitoring during the experiment indicates that sites had similar temperatures, especially during the growing season, such that the two sites roughly represent replicates in terms of climate.

At both sites, treatments were positioned in both closed (40-60 year old mixed aspen-birch-fir) and relatively open (recently cleared) overstory conditions. The overall experimental design was a 2 (site) $* 2$ (habitat) $* 3$ (treatment) factorial, with six replicates of each for a total of 72 circular $3-\mathrm{m}$ diameter plots. Treatments included three levels of simultaneous plant and soil warming (ambient, $+1.7^{\circ} \mathrm{C}$, $+3.4^{\circ} \mathrm{C}$ ), all of which included infrared lamp heaters and soil heating cables (dummy lamps and cables in the ambient plots). For this study we used the 48 plots exposed to ambient or $+3.4^{\circ} \mathrm{C}$ warming. Warming was implemented from early spring to late fall each year in open air (that is, without chambers) via a feedback control that acts concurrently and independently at the plot scale to maintain a fixed temperature differential from ambient conditions above- and belowground. On average, we achieved $24-\mathrm{h} \mathrm{d}^{-1}$ warming of $+3.4{ }^{\circ} \mathrm{C}$ (roughly April-November) and midsummer midday (0900-1,500 h during June-Sept) aboveground warming of $+2.9^{\circ} \mathrm{C}$ across the 2009 to 2011 growing seasons.

Seedlings of the 11 tree species were planted into existing shrub, herb and fern vegetation in each plot. Vegetation densities were high, as is typical for this region. The planted juveniles included six native broadleaf, one naturalized broadleaf and four native needleleaf species, all of which are present in the ecotonal region. Local ecotypes of all native seedlings were obtained from the Minnesota Department of Natural Resources; Rhamnus seedlings were transplanted from northern Minnesota forests. Methods of defining the indices of species range limits and local ecotypic distributions are provided in the Supplementary Information.

Growth and gas-exchange measurements and statistical analyses. Tree diameter and height were measured each fall $(2009,2010,2011)$ for all individuals. Total stem biomass in 2011 for 4,118 individuals was estimated from a regression relation (from 790 trees harvested in 2011) that described biomass as a function of diameter and height $\left(R^{2}=0.95, P<0.0001\right)$. Mortality was very low for almost all species in all treatments. Here we show stem biomass growth responses, as these integrate diameter and height growth. We measured light-saturated net photosynthetic rates in situ in morning or early afternoon across the growing season in 2009, 2010 and 2011. A total of >4,400 measurements of net photosynthesis were made across species, treatments, sites and time. In situ measures of light-saturated net photosynthesis were made using six Li-Cor 6400 portable photosynthesis systems (Li-Cor, Lincoln, NE). Measurements were made throughout the growing seasons (June to September) of 2009 through 2011 under generally comparable conditions across species (Supplementary Table 2).

Multi-factor analyses of variance were used to compare net photosynthetic rates to treatment combinations. Models included the following independent variables: site, species, overstory condition, warming treatment and all 2- and 3 -way interactions among variables. For analysis of growth, we used stem biomass at the end of the growing season in 2011 as the dependent variable and used the stem diameter in 2008 as a covariate. For additional information, see Supplementary Information.

Received 9 July 2014; accepted 11 December 2014; published online 19 January 2015 


\section{References}

1. Walther, G-R. Community and ecosystem responses to recent climate change. Proc. R. Soc. Lond. B 365, 2019-2024 (2010)

2. Pucko, C., Beckage, B., Perkins, T. \& Keeton, W. S. Species shifts in response to climate change: Individual or shared responses? J. Torrey Bot. Soc. 138, 156-176 (2011)

3. Davis, M. B. \& Shaw, R. G. Range shifts and adaptive responses to Quaternary climate change. Science 292, 673-679 (2001).

4. Reich, P. B. \& Oleksyn, J. Climate warming will reduce growth and survival of Scots pine except in the far north. Ecol. Lett. 11, 588-597 (2008).

5. Friedman, S. K. \& Reich, P. B. Regional legacies of logging: Departure from presettlement forest conditions in northern Minnesota. Ecol. Appl. 15, 726-744 (2005)

6. Rich, R. L. et al. Design and performance of combined infrared canopy and belowground warming in the B4WarmED (Boreal Forest Warming at an Ecotone in Danger) experiment. Glob. Change Biol. (in the press).

7. Peng, C. et al. A drought-induced pervasive increase in tree mortality across Canada's boreal forests. Nature Clim. Change 1, 467-471 (2011).

8. Ma, Z. et al. Regional drought-induced reduction in the biomass carbon sink of Canada's boreal forests. Proc. Natl Acad. Sci. USA 109, 2423-2427 (2012).

9. Fisichelli, N., Frelich, L. E. \& Reich, P. B. Sapling growth responses to warmer temperatures 'cooled' by browse pressure. Glob. Change Biol. 18, 3455-3463 (2012).

10. Iverson, L. R. \& Prasad, A. M. Predicting abundance of 80 tree species following climate change in the eastern United States. Ecol. Monogr. 68, 465-485 (1998).

11. Sakai, A. \& Weiser, C. J. Freezing resistance of trees in North America with reference to tree regions. Ecology 54, 118-126 (1973).

12. Strimbeck, G. R., Kjellsen, T. D., Schaberg, P. G. \& Murakami, P. F. Dynamics of low-temperature acclimation in temperate and boreal conifer foliage in a mild winter climate. Tree Physiol. 28, 1365-1374 (2008).

13. Loehle, C. Height growth rate tradeoffs determine northern and southern range limits for trees. J. Biogeogr. 25, 735-742 (1998).

14. Koehler, G. et al. Proteomic study of low-temperature responses in strawberry cultivars that differ in cold tolerance. Plant Physiol. 159, 1787-1805 (2012).

15. Savage, J. A. \& Cavender-Bares, J. Phenological cues drive an apparent trade-off between freezing tolerance and growth in the family Salicaceae. Ecology 94, 1708-1717 (2013).

16. Rehfeldt, G. E., Ying, C. C., Spittlehouse, D. L. \& Hamilton, D. A. Jr Genetic responses to climate in Pinus contorta: Niche breadth, climate change, and reforestation. Ecol. Monogr. 69, 375-407 (1999).

17. Hughes, A. R., Inouye, B. D., Johnson, M. T. J., Underwood, N. \& Vellend, M. Ecological consequences of genetic diversity. Ecol. Lett. 11, 609-623 (2008).

18. Barbour, R. C. et al. A geographic mosaic of genetic variation within a foundation tree species and its community-level consequences. Ecology 90, 1762-1772 (2009).

19. Cahill, A. E. et al. How does climate change cause extinction? Proc. R. Soc. Lond. B 280, 20121890 (2013).

20. Messaoud, Y., Bergeron, Y. \& Asselin, H. Reproductive potential of balsam fir (Abies balsamea), white spruce (Picea glauca), and black spruce (P. mariana) at the ecotone between mixedwood and coniferous forests in the boreal zone of western Quebec. Am. J. Bot. 94, 746-754 (2007).

21. Burns, R. M. \& Honkala, B. H. Silvics of North America Vol. 1 (Agriculture Handbook 654, US Department of Agriculture, Forest Service, 1990).
22. Burns, R. M. \& Honkala, B. H. Silvics of North America Vol. 2 (Agriculture Handbook 654, US Department of Agriculture, Forest Service, 1990).

23. Guisan, A. \& Thuiller, W. Predicting species distribution: Offering more than simple habitat models. Ecol. Lett. 8, 993-1009 (2005).

24. Bakkenes, M., Alkemade, J. R. M., Ihle, F., Leemans, R. \& Latour, J. B. Assessing effects of forecasted climate change on the diversity and distribution of European higher plants for 2050. Glob. Change Biol. 8, 390-407 (2002).

25. Midgley, G. F., Hannah, L., Millar, D., Thuiller, W. \& Booth, A. Developing regional and species-level assessments of climate change impacts on biodiversity in the Cape Floristic Region. Biol. Conserv. 112, 87-97 (2003).

26. Thuiller, W., Lavorel, S., Midgley, G. F., Lavergne, S. \& Rebelo, A. G. Relating plant traits and species distributions along bioclimatic gradients for 88 Leucadendron species in the Cape Floristic Region. Ecology 85, 1688-1699 (2004)

27. Heinselman, M. Fire in the virgin forests of the Boundary Waters Canoe Area Minnesota. Quat. Res. 3, 329-382 (1973).

28. Grigal, D. F. \& Ohmann, L. F. Classification, description, and dynamics of upland plant communities within a Minnesota wilderness area. Ecol. Monogr. 45, 389-407 (1975).

29. Sendall, K. M. et al. Acclimation of photosynthetic temperature optima of temperate and boreal tree species in response to experimental forest warming. Glob. Change Biol. http://dx.doi.org/10.1111/gcb.12781 (2014).

30. Price, D. T. et al. Anticipating the consequences of climate change for Canada's boreal forest ecosystems. Environ. Rev. 21, 322-365 (2013).

31. Bradshaw, R. H. W. \& Zackrisson, O. A two thousand year record of a northern Swedish boreal forest stand. J. Vegetation Sci. 1, 519-528 (1990).

32. Rich, R. L., Frelich, L. E. \& Reich, P. B. Windthrow mortality in the southern boreal forest: Effects of species, diameter, and stand age. J. Ecol. 95, 1261-1273 (2007)

\section{Acknowledgements}

This research was supported by the Office of Science (BER), US Department of Energy, 385 Grant No. DE-FG02-07ER64456, by the Minnesota Department of Natural Resources, and by the College of Food, Agricultural, and Natural Resources Sciences and Wilderness Research Foundation, University of Minnesota. Assistance with experimental operation and data collection was provided by C. Buschena, C. Zhao, K. Gill, H. Jihua $\mathrm{X}$. Wei and numerous summer interns. We also thank N. Danz, J. Almendinger and $\mathrm{K}$. Zhu for assistance in identifying the range limits and local ecotonal distributions of species, and A. Pierce for operational support.

\section{Author contributions}

P.B.R., R.A.M., S.E.H. and R.L.R. designed the study. R.L.R. designed the warming system. K.M.S., K.R. and A.S. implemented the warming system and/or day-to-day field measurements. P.B.R. analysed the data. P.B.R. and the other co-authors jointly wrote the manuscript.

\section{Additional information}

Supplementary information is available in the online version of the paper. Reprints and permissions information is available online at www nature com/reprints.

Correspondence and requests for materials should be addressed to P.B.R.

\section{Competing financial interests}

The authors declare no competing financial interests. 